\title{
Remifentanil provides better analgesia than alfen- tanil during breast biopsy surgery under monitored anesthesia care
}

\author{
[Le rémifentanil fournit une meilleure analgésie que l'alfentanil pendant la \\ biopsie mammaire réalisée sous surveillance anesthésique]
}

John A. Dilger MD, * Juraj Sprung MD PhD, ${ }^{*}$ Walter Maurer MD, $\dagger$ John Tetzlaff MD $\dagger$

Purpose: To compare the analgesic effects of remifentanil and alfentanil during breast biopsy under monitored anesthesia care (MAC).

Methods: Sixty patients received sedation with propofol (50 $\mu \mathrm{g} \cdot \mathrm{kg}^{-1} \cdot \mathrm{min}^{-1}$ ). After receiving a loading dose of opioid (either remifentanil $0.5 \mu \mathrm{g} \cdot \mathrm{kg}^{-1}$, or alfentanil $2.5 \mu \mathrm{g} \cdot \mathrm{kg}^{-1}$ ), an infusion was initiated (remifentanil $0.05 \mu \mathrm{g} \cdot \mathrm{kg}^{-1} \cdot \mathrm{min}^{-1}$ or alfentanil 0.25 $\left.\mu \mathrm{g} \cdot \mathrm{kg}^{-1} \cdot \mathrm{min}^{-1}\right)$, and this was supplemented with local anesthetic infiltration. The pain was evaluated with a ten-point visual analogue scale (VAS) during local anesthetic infiltration and deep tissue dissection. Inadequate analgesia, defined as VAS scores $\geq 5$, was treated first with boluses of opioid (remifentanil group $10 \mu \mathrm{g}$ or alfentanil group $50 \mu \mathrm{g}$ ) and if inadequate after two treatments with additional local anesthetic. Postoperative times were recorded including the times until discharge criteria were achieved and patient's actual discharge.

Results: The pain scores were similar between the two groups during the initial injections of local anesthetic in the breast, however, patients in the remifentanil group had lower mean pain scores during deep tissue dissection $(2.3$ vs $4.3, P<0.01$ ). Patients in the remifentanil group required fewer rescue doses of opioid ( 1.9 vs 3.6, $P<0.03$ ) and local anesthetic (5 vs I5, $P<0.006$ ). The two study groups had comparable speed of recovery.

Conclusion: Remifentanil was a better opioid choice than alfentanil for breast biopsy under MAC at the doses studied, but it did not increase the rapidity in which patients recovered postoperatively.
Objectif : Comparer les effets analgésiques du rémifentanil et de l'alfentanil pendant la biopsie mammaire sous surveillance anesthésique (SA).

Méthode : Soixante patientes ont reçu une sédation avec du propofol (50 $\left.\mu \mathrm{g} \cdot \mathrm{kg}^{-1} \cdot \mathrm{min}^{-1}\right)$. Après une dose de charge d'opioïde (soit le rémifentanil $0,5 \mu \mathrm{g} \cdot \mathrm{kg}^{-1}$ ou l'alfentanil $2,5 \mu \mathrm{g} \cdot \mathrm{kg}^{-1}$ ), une perfusion a été amorcée $\left(0,05 \mu \mathrm{g} \cdot \mathrm{kg}^{-1} \cdot \mathrm{min}^{-1}\right.$ de rémifentanil ou 0,25 $\mu \mathrm{g} \cdot \mathrm{kg}^{-1} \cdot \mathrm{min}^{-1}$ d'alfentanil) et complétée par une infiltration d'anesthésique local. La douleur a été évaluée avec une échelle visuelle analogique en dix points (EVA) pendant l'infiltration et la dissection des tissus profonds. L'analgésie incomplète, définie par un score $\geq 5$ à l'EVA, a été traitée d'abord avec des bolus d'opioïde ( 10 $\mu g$ de rémifentanil ou $50 \mu \mathrm{g}$ d'alfentanil), puis avec un anesthésique local si l'analgésie était incomplète après deux doses. Après l'opération, nous avons noté le délai nécessaire à l'atteinte des critères de sortie et le temps réel avant la sortie des patientes.

Résultats : Les scores de douleur ont été similaires dans les deux groupes pendant les injections initiales d'anesthésique local dans le sein, quoique les patientes qui ont reçu le rémifentanil aient présenté des scores de douleur moyens plus bas pendant la dissection tissulaire $(2,3$ vs $4,3, P<0,01)$. Les patientes sous rémifentanil ont demandé moins d'opioïde de secours $(1,9$ vs 3,6, $P<0,03)$ et d'anesthésique local (5 vs 15, $P<0,006)$. Les temps de récupération ont été comparables entre les groupes.

Conclusion : Le choix du rémifentanil s'est révélé meilleur que celui de l'alfentanil pour la biopsie mammaire sous SA aux doses étudiées, mais n'a pas raccourci la récupération postopératoire.

From the Departments of Anesthesiology, Mayo Clinic, ${ }^{*}$ Rochester, Minnesota, and The Cleveland Clinic Foundation, $\dagger$ Cleveland, Ohio, USA.

Address correspondence to: Dr. John A. Dilger, Department of Anesthesiology, Mayo Clinic, 200 First Street, S.W., Rochester,

Minnesota 55905, USA. Phone: 507-284-9700; Fax: 507-284-0120; E-mail: dilger.john@mayo.edu

This work has been performed at the Cleveland Clinic Foundation.

Funding: This work has been funded by the Departmental funds at the Cleveland Clinic Foundation.

Accepted for publication May 26, 2003.

Revision accepted September 10, 2003. 
B REAST biopsy is a stimulating outpatient procedure which may be performed either under general anesthesia or local anesthesia with monitored anesthesia care (MAC). MAC with local infiltration may be preferred to general anesthesia as it may allow a faster recovery. An ideal anesthetic for sedation during MAC is propofol because of its fast onset, easy titration and fast offset. ${ }^{1}$ This technique is frequently supplemented with iv analgesics for the control of discomfort associated with local anesthetic injection and for the breakthrough pain when the surgical field cannot be completely anesthetized with local anesthetic. Alfentanil and remifentanil have rapid onset and short-acting opioid effects and are suitable for pain control during outpatient surgery. ${ }^{1}$ By combining opioids and sedatives with local infiltration, anesthesiologists can provide optimal comfort while achieving a fast recovery with few side effects. Remifentanil is an ideal opioid agonist for outpatient procedures because it has a very quick onset while its duration of action is shorter than that of alfentanil. Being metabolized by non-specific plasma and tissue esterases, ${ }^{2,3}$ remifentanil has a context sensitive half-life of three to six minutes which is independent of the dose or duration of administration. ${ }^{4,5}$ Because of its unique metabolism respiratory depression and sedation after its discontinuation are of short duration and emergence is very rapid. ${ }^{6}$

The purpose of this study was to test the hypothesis that remifentanil may be an advantageous opioid over alfentanil for breast biopsy surgery. We hypothesized that pain scores would be lower, that patients would be discharged faster from the hospital as a result of the drug's rapid metabolism, and that patient satisfaction would be superior.

\section{Methods}

In this prospective, randomized, double-blinded study we compared the use of remifentanil to alfentanil for analgesia during open breast biopsy or needle localized breast surgeries. The Cleveland Clinic Investigational Review Board approved the study protocol, and all participants signed informed consent agreements. A total of 63 ASA physical status I-III patients were enrolled in the study. Two patients in the remifentanil group and one patient in the alfentanil group were eliminated from the study due to extreme anxiety requiring general anesthesia prior to incision. This resulted in two equal groups of 30 patients each (Table I). We excluded the following patients/conditions: hypersensitivity or intolerance to opioids, chronic use of opioids for pain, alcohol or drug abuse, and those who were morbidly obese [body mass index $(\mathrm{BMI})>35$ ]. The opioid solutions were prepared by an anesthesia provider not involved in the study who provided both bolus and maintenance syringes for the two groups. The anesthesiologist was blinded to the opioid used during the surgery. The maintenance concentrations were adjusted to 10 $\mu \mathrm{g} \cdot \mathrm{mL}^{-1}$ for remifentanil and $50 \mu \mathrm{g} \cdot \mathrm{mL}^{-1}$ for the alfentanil, so the infusion rates in both groups, in millilitres per hour, were the same.

The patients received no premedication before surgery. After routine anesthesia monitors were placed sedation was initiated. Both groups initially received propofol $1 \mathrm{mg} \cdot \mathrm{kg}^{-1}$ mixed with $20 \mathrm{mg}$ of lidocaine followed by a $50 \mu \mathrm{g} \cdot \mathrm{kg}^{-1} \cdot \mathrm{min}^{-1}$ propofol infusion. After receiving a loading dose of opioid (remifentanil group $0.5 \mu \mathrm{g} \cdot \mathrm{kg}^{-1}$ or alfentanil group $\left.2.5 \mu \mathrm{g} \cdot \mathrm{kg}^{-1}\right)$, continuous infusions were initiated: remifentanil 0.05 $\mu \mathrm{g} \cdot \mathrm{kg}^{-1} \cdot \mathrm{min}^{-1}$ or alfentanil $0.25 \mu \mathrm{g} \cdot \mathrm{kg}^{-1} \cdot \mathrm{min}^{-1}$. Five minutes after the study drug was started, local infiltration was performed by the surgeon using $1 \%$ lidocaine with epinephrine 1:200,000.

During surgery heart rate, blood pressure, oxyhemoglobin saturation $\left(\mathrm{SpO}_{2}\right)$, and respiratory rate were recorded at baseline and throughout the procedure. Study personnel (anesthesiologist in charge or anesthesia research personnel) evaluated the level of pain with a ten-point visual analogue scale (VAS) during local anesthetic infiltration and during the deep dissection of the breast tissue. The patients were asked to rate their pain scores verbally. In addition, at the same time the level of sedation was assessed by using the Observer's Assessment of Alertness/Sedation (OAA/S) scale, with $5=$ awake/alert to $\mathrm{l}=$ asleep/unarousable. Providing $\mathrm{OAA} / \mathrm{S}$ was rated as 1 , and the patient did not show physical evidence of pain (grimacing, moving, etc.), the VAS was counted as 0 (no pain). Inadequate analgesia, defined as VAS scores $\geq 5$, was treated first with boluses of opioid solution (remifentanil $10 \mu \mathrm{g}$ or alfentanil $50 \mu \mathrm{g}$ ) and, if inadequate after two treatments, with the additional infiltration of the surgical field with local anesthetic. The number of opioid boluses and volumes and numbers of local anesthetic boluses were recorded for analysis. Patients were monitored for signs of excessive sedation. The opioid infusion was scheduled to be discontinued if the respiratory rate was less than 8 breaths. $\mathrm{min}^{-1}$ or if despite supplemental oxygen, the pulse oximetry values were below $90 \%$. If respiration was unaffected, the propofol and study infusions were continued unchanged until skin closure. The last skin stitch was counted as the end of surgery to calculate the length of the procedure.

Patients were transferred to the step down recovery (phase II) unit after surgery. We recorded the time until discharge criteria were achieved, and the time 
when the patient was actually discharged. Qualifications for discharge from phase II were defined as a postanesthesia discharge score $\geq 9$ (two points each for vital signs, pain, activity, bleeding, and oral intake and voiding). We also recorded time until unassisted ambulation was achieved and the level of pain. Nausea and vomiting were scored on a fourpoint scale $(0=$ none, $1=$ mild, $2=$ modest, and $3=$ severe). Patients were contacted by telephone the day after surgery and asked about their satisfaction with the pain control during the operation $(1=$ extremely satisfied, $7=$ extremely dissatisfied). They were also asked if they would choose to have the same anesthetic for another procedure.

Statistical analyses were performed using the twotailed Student $t$ test, Fisher exact test, and Wilcoxon rank sum test (nausea and satisfaction scores) when appropriate, and $P$ values $<0.05$ were considered statistically significant. The values are presented as mean \pm standard deviation.

\section{Results}

The two study groups were comparable in age, weight, ASA physical status, length of surgery, and number of patients who underwent the two types of breast biopsies (Table I). Neither group had significant hypotension, bradycardia, or respiratory depression requiring alteration of opioid infusion.

There were no differences between the remifentanil and alfentanil groups in OAA/S scores during either local anesthetic infiltration or deep tissue dissection (Table II). Similar volumes of local anesthetic were used to infiltrate the breast tissue prior to incision in both groups. While the VAS pain scores were not different during the initial local anesthetic injection, during deep tissue dissection patients in the remifentanil group had lower mean pain scores ( 2.3 vs 4.3 , respectively, $P<$ $0.01)$. Furthermore, remifentanil patients received fewer rescue doses of opioids than patients in the alfentanil group (1.9 vs 3.6, $P<0.03$ ). Significantly more patients in the alfentanil group received rescue doses of local anesthetic (5 vs 15 patients in remifentanil and alfentanil groups, respectively, $P<0.006$, Table II). Furthermore, patients requiring rescue doses of local anesthetic received more local anesthetic in the alfentanil (average $10.4 \mathrm{~mL}$ ) than in the remifentanil (average $5.5 \mathrm{~mL}$ ) group (Table II).

None of the postoperative outcome variables (Table III) were different; time for ambulation, achievement of discharge criteria, and actual discharge were similar in the two groups, as was the incidence of nausea or vomiting. The postoperative follow-up interview regarding patient's satisfaction with surgery
TABLE I Demographics and surgery characteristics

\begin{tabular}{lll}
\hline & Remifentanil & Alfentanil \\
\hline Patients $(n)$ & 30 & 30 \\
Age $(\mathrm{yr})$ & $44.0 \pm 10.6$ & $44.7 \pm 10.8$ \\
Weight $(\mathrm{kg})$ & $62.5 \pm 9.4$ & $65.8 \pm 8.8$ \\
ASA $(\mathrm{I} / \mathrm{II} / \mathrm{III})(n)$ & $14 / 11 / 5$ & $15 / 12 / 3$ \\
Biopsy type $(n)$ & & \\
Open & 25 & 28 \\
Needle localization & 5 & 2 \\
Duration of procedure $(\mathrm{min})$ & $33.5 \pm 9.6$ & $37.9 \pm 11.7$ \\
\hline
\end{tabular}

Values are mean $\pm \mathrm{SD} ;(n)=$ number of patients.

TABLE II Sedation/pain scores, anesthetic and opioid doses used during the surgery

\begin{tabular}{|c|c|c|c|}
\hline & Remifentanil & Alfentanil & $P$ \\
\hline \multicolumn{4}{|l|}{ Sedation scores during* } \\
\hline $\begin{array}{l}\text { Local anesthetic } \\
\text { infiltration }\end{array}$ & $2.3 \pm 0.50$ & $2.3 \pm 4.6$ & 1.0 \\
\hline Deep tissue dissection & $1.1 \pm 0.5$ & $0.9 \pm 0.4$ & 0.16 \\
\hline \multicolumn{4}{|l|}{ Pain scores duringt } \\
\hline $\begin{array}{l}\text { Local anesthetic } \\
\text { injection }\end{array}$ & $2.3 \pm 2.2$ & $2.3 \pm 2.6$ & 1.0 \\
\hline Deep tissue dissection & $2.3 \pm 3.0$ & $4.3 \pm 3.1$ & $<0.01$ \\
\hline \multicolumn{4}{|l|}{ Local anesthetic given } \\
\hline Initial injection $\ddagger(\mathrm{mL})$ & $10.0 \pm 1.1$ & $10.9 \pm 1.6$ & 0.9 \\
\hline Rescue injection $\$(\mathrm{~mL})$ & $5.5 \pm 2.5$ & $10.4 \pm 5.4$ & $<0.02$ \\
\hline Rescue injection $(n)$ & $5 / 30(17 \%)$ & $15 / 30(50 \%)$ & $<0.006$ \\
\hline \multicolumn{4}{|l|}{ Opioids given } \\
\hline $\begin{array}{l}\text { Rescue doses } \\
\text { opioids } \$\end{array}$ & $1.9 \pm 1.0$ & $3.6 \pm 2.5$ & $<0.03$ \\
\hline $\begin{array}{l}\text { Rescue doses } \\
\text { opioids }(n)\end{array}$ & $\begin{array}{l}13 / 30 \\
(43.3 \%)\end{array}$ & $\begin{array}{l}19 / 30 \\
(63.3 \%)\end{array}$ & $<0.09$ I \\
\hline
\end{tabular}

Values are mean $\pm \mathrm{SD} ;{ }^{*}$ Observer's assessment of alertness/sedation scale; †Visual analogue scale; $\ddagger$ Average for all patients; $\$$ Average of all patients who received any rescue injection; $n=$ number of patient who received rescue dose/total number of patients; $\%=$ percentage of patients who received rescue dose; IFisher exact test. All other comparisons were performed using a two-sample t test.

revealed similar overall satisfaction between the two groups. Most of the patients in the two groups were very satisfied with their anesthetic treatment (Table III), and only two patients were less than somewhat dissatisfied and rated their satisfaction scores 4 and 6 in the alfentanil and remifentanil groups, respectively.

\section{Discussion}

We compared the use of remifentanil and alfentanil for analgesia in patients undergoing ambulatory breast biopsy under MAC. We selected doses of opioids which have been reported previously for surgeries under 
TABLE III Postoperative period: indicators of patients satisfaction and discharge times

\begin{tabular}{llll}
\hline & Remifentanil & Alfentanil & $P \dagger$ \\
\hline Pain scores & $0.5 \pm 0.9$ & $0.3 \pm 0.7$ & 0.265 \\
Nausea, $n(\%)$ & & & 0.401 \\
$\quad$ - None & $28(93)$ & $26(87)$ & \\
$\quad$ - Mild & $2(7)$ & $4(13)$ & \\
$\quad$ - Moderate & $0(0)$ & $0(0)$ & \\
$\quad$ - Severe & $0(0)$ & $0(0)$ & \\
Time to ambulation (min) & $46 \pm 22$ & $43 \pm 16$ & 0.638 \\
Discharge criteria met (min) & $54 \pm 24$ & $53 \pm 15$ & 0.810 \\
Actual discharge (min) & $69 \pm 28$ & $76 \pm 24$ & 0.534 \\
Satisfaction, ${ }^{*} n$ (\%) & & & 0.792 \\
$\quad$ - Extremely satisfied & $24(80)$ & $25(83)$ & \\
$\quad$ - Satisfied & $5(17)$ & $3(10)$ & \\
- Somewhat satisfied & $0(0)$ & $1(3)$ & \\
- Neutral & $0(0)$ & $1(3)$ & \\
- Somewhat dissatisfied & $0(0)$ & $0(0)$ & \\
- Dissatisfied & $1(3)$ & $0(0)$ & \\
- Extremely dissatisfied & $0(0)$ & $0(0)$ & \\
\hline
\end{tabular}

Values are mean $\pm S D$, unless otherwise indicated. *Score was obtained postoperatively by telephone interview. $†$ Nausea and satisfaction scores were compared using the Wilcoxon rank sum test, and all other comparisons were performed using a two-sample $t$ test. Times rounded to the nearest minute.

MAC. ${ }^{1,7-10}$ We found that the pain scores were similar between the two groups during the initial use of local anesthetic for field infiltration, however, the patients in the remifentanil group had lower pain scores during deep tissue dissection, which was the most stimulating part of the procedure. Patients in the remifentanil group required fewer rescue doses of opioid and local anesthetic for breakthrough pain. The two study groups had comparable speed of recovery and patient satisfaction. Therefore, when compared to alfentanil, remifentanil is a better opioid choice for ambulatory breast biopsy under MAC at the doses studied. Despite its faster elimination, remifentanil did not increase the rapidity in which patients recovered postoperatively.

It has been shown that remifentanil is eight to 20 times more potent than alfentanil. ${ }^{11,12}$ In the present study we compared remifentanil to alfentanil in a 1:5 ratio and, at this ratio, remifentanil was a better analgesic during deep dissection of the breast tissue. The analgesic properties of remifentanil have been compared to those of alfentanil in other MAC settings. During retrobulbar blockade, patients received remifentanil or alfentanil, and those who received remifentanil had less pain during the initiation of the block. ${ }^{13}$ In contrast, in our study, initiation of blockade with lidocaine resulted in similar pain scores in the two groups. This difference may be explained by the more stimulating nature of retrobulbar block compared to the simple infiltration of breast tissue. In another study remifentanil was compared to other opioids during extracorporeal shock wave lithotripsy performed under MAC. ${ }^{14}$ Patients in this study were randomized to received remifentanil, alfentanil, sufentanil or fentanyl in a bolus fashion. Boluses of remifentanil, sufentanil, and fentanyl provided effective analgesia for lithotripsy, but remifentanil provided significantly superior analgesia compared to alfentanil ${ }^{14}$ which is in agreement with our study.

Remifentanil is 40 times more potent than alfentanil with respect to affecting minute ventilation, ${ }^{15}$ but, in our spontaneously breathing patients, there were no cases of ventilatory depression that required discontinuation of the opioid infusion. Furthermore, one may expect to encounter more pain postoperatively when remifentanil is used compared to other opioids due to the quick dissipation of its analgesic action. ${ }^{14}$ This was not the case in our study presumably because we used lidocaine to infiltrate the operative field, and this provided adequate postoperative analgesia.

Recovery times and times to discharge have been evaluated with remifentanil and alfentanil in several studies. In a study by Cartwright et al., ${ }^{16}$ ambulatory surgery patients received general anesthesia consisting of air/isoflurane and infusions of remifentanil or alfentanil which were maintained until the end of surgery. There was no detectable difference between the groups in times to eligibility for discharge, actual discharge, or the presence of nausea and vomiting. ${ }^{16}$ Similar results were obtained by Kovac et al. ${ }^{17}$ in which patients received general anesthesia (nitrous oxide/oxygen) and were randomized to receive either remifentanil or alfentanil. Regardless of the opioid received, the patients were discharged from the recovery room in similar times and with similar incidences of nausea and vomiting. These findings are in agreement with our results despite our expectations that remifentanil patients would be discharged sooner because of its rapid elimination. The remifentanil patients in our study were eligible and ultimately discharged no sooner than the alfentanil patients, and they had similar incidence of nausea and vomiting.

In conclusion, during breast biopsy the use of remifentanil for analgesia was superior to alfentanil in providing lower pain scores while requiring fewer treatments with opioids and local anesthetics. At the same time, the short activity of the remifentanil did not allow patients to recover at an accelerated rate and did not result in difference in pain scores during the recovery period. 


\section{References}

1 Avramov MN, White PF. Use of alfentanil and propofol for outpatient monitored anesthesia care: determining the optimal dosing regimen. Anesth Analg 1997; 85: 566-72.

2 Feldman PL, James MK, Brackeen MF, et al. Design, synthesis, and pharmacological evaluation of ultrashortto long-acting opioid analgetics. J Med Chem 1991; 34: 2202-8.

3 James MK, Feldman PL, Schuster SV, Bilotta JM, Brackeen MF, Leighton HJ. Opioid receptor activity of GI $87084 \mathrm{~B}$, a novel ultra-short acting analgesic, in isolated tissues. J Pharmacol Exp Ther 1991; 259: 712-8.

4 Hughes MA, Glass PS, Jacobs JR. Context-sensitive halftime in multicompartment pharmacokinetic models for intravenous anesthetic drugs. Anesthesiology 1992; 76: 334-41.

5 Westmoreland CL, Hoke JF, Sebel PS, Hug CC Jr, Muir KT. Pharmacokinetics of remifentanil (GI87084B) and its major metabolite (GI90291) in patients undergoing elective inpatient surgery. Anesthesiology 1993; 79: 893-903.

6 Rosow C. Remifentanil: a unique opioid analgesic (Editorial). Anesthesiology 1993; 79: 875-6.

7 Servin FS, Raeder JC, Merle JC, et al. Remifentanil sedation compared with propofol during regional anaesthesia. Acta Anaesthesiol Scand 2002; 46: 309-15.

8 Sa Rego MM, Inagaki $\Upsilon$, White PF. Remifentanil administration during monitored anesthesia care: are intermittent boluses an effective alternative to a continuous infusion? Anesth Analg 1999; 88: 518-22.

9 Holas A, Krafft P, Marcovic M, Quehenberger F. Remifentanil, propofol or both for conscious sedation during eye surgery under regional anaesthesia. Eur J Anaesthesiol 1999; 16: 741-8.

10 Ganzberg S, Pape RA, Beck FM. Remifentanil for use during conscious sedation in outpatient oral surgery. J Oral Maxillofac Surg 2002; 60: 244-50; discussion 250-1.

11 Hoke JF, Cunningham F, James MK, Muir KT, Hoffman WE. Comparative pharmacokinetics and pharmacodynamics of remifentanil, its principle metabolite (GR90291) and alfentanil in dogs. J Pharmacol Exp Ther 1997; 281: 226-32.

12 Egan TD, Minto CF, Hermann DJ, Barr J, Muir KT, Shafer SL. Remifentanil versus alfentanil: comparative pharmacokinetics and pharmacodynamics in healthy adult male volunteers. Anesthesiology 1996; 84: 821-33.

13 Abmad S, Leavell ME, Fragen RJ, Jenkins W, Roland $C L$. Remifentanil versus alfentanil as analgesic adjuncts during placement of ophthalmologic nerve blocks. Reg Anesth Pain Med 1999; 24: 331-6.
14 Gesztesi Z, Rego MM, White PF. The comparative effectiveness of fentanyl and its newer analogs during extracorporeal shock wave lithotripsy under monitored anesthesia care. Anesth Analg 2000; 90: 567-70.

15 Glass PS, Iselin-Chaves IA, Goodman D, Delong E, Hermann DJ. Determination of the potency of remifentanil compared with alfentanil using ventilatory depression as the measure of opioid effect. Anesthesiology 1999; 90: 1556-63.

16 Cartwright DP, Kvalsvik O, Cassuto J, et al. A randomized, blind comparison of remifentanil and alfentanil during anesthesia for outpatient surgery. Anesth Analg 1997; 85: 1014-9.

17 Kovac AL, Azad SS, Steer P, Witkowski T, Batenhorst R, $\mathrm{McNeal} S$. Remifentanil versus alfentanil in a balanced anesthetic technique for total abdominal hysterectomy. J Clin Anesth 1997; 9: 532-41. 